\title{
The Case for the Odd Case, Research Reviews, Parenting Pandas
}

\author{
Nancy L. Segal \\ Department of Psychology, California State University, USA
}

$\mathrm{M}$ any twin researchers occasionally encounter twin pairs displaying unusual physical, medical or behavioral traits. Unfortunately, these interesting cases are often unreported because they do not fit in easily with ongoing projects. However, these "odd cases" may suggest new hypotheses, new designs or entirely new projects. In this paper, I argue in favor of publishing case studies of exceptional twins, and refer to several large scale studies inspired by such reports. Several informative case studies are then summarized: DZ twins discordant for hyperinsulinism, DZ twins born after ICSI, "simultaneous madness in twins, and sixteenth century conjoined twins. The article concludes with a review of parenting twin pandas.

\section{The Case for the Odd Case}

They are the pairs that are unpublished, but they are the ones we remember. These twins' psychological and biological circumstances are highly unusual, placing them beyond the limits of conventional samples. Their exclusion can avoid biased findings, but their neglect can limit new endeavors. Selected pairs sometimes appear as case reports, but too often only small numbers of colleagues hear about them at coffee breaks and cocktail hours.

Most researchers, including myself, have been captivated by the unique physical or behavioral attributes of particular twin pairs. Rather than relegate their files to the backs of storage closets, it may be worth re-examining these sets. Such efforts may inspire fresh hypotheses, innovative designs or entirely new projects. Similarly, investigators accustomed to working with large twin samples may overlook single case reports in professional journals. However, valuable information is often found in such neglected sources.

This article is intended to sharpen readers' sensitivity to, and appreciation for, "odd cases" as potential avenues for advancing research agendas. The idea is to demonstrate the essential compatibility between these two approaches to twin studies. I will begin with my own ongoing project of virtual twins.

\section{Virtual Twins}

I will forever be indebted to Judy Punčochàr̆, a former graduate student at the University of Minnesota, for alerting me to this unusual kinship. Knowing my interest in twins, she explained that she was the mother of two young boys who were five days apart, but who shared no biological link. How did this happen? After several unsuccessful pregnancy attempts, Judy decided to adopt a child, but with that process moving forward she became pregnant. Then, just four days before delivering her son, a male infant became available for adoption and she was delighted to take him. I was charmed by the idea of these strangely crafted "twins", especially by their untapped potential to reveal the extent of shared environmental influences on development. I also wondered about the degree of affiliation they might feel, relative to ordinary MZ twins, DZ twins and best friends.

I invited the boys to visit my laboratory and administered a standard twin protocol. This consisted of family background forms, social relationship surveys, intelligence tests and behavioral observations. This was done with the intention of producing a possible case study that could be meaningful when viewed against the backdrop of existing $\mathrm{MZ}$ and $\mathrm{DZ}$ twin data. I never intended to undertake a large-scale study, feeling certain that such siblings would be extremely rare. I was wrong. Judy alerted me to a second pair in another state, and then two additional pairs suddenly appeared. Years later, a reviewer on a paper also wondered about the frequency of these pairs, then realized she knew several sets from high school! I have currently studied over 100 pairs. I now call them virtual twins, a label suggested by one of the families.

Virtual twins (VTs) are formally defined as unrelated children of the same age, reared together since infancy. They may include two adoptive siblings or one adoptee and one biological child. The age criteria for inclusion in the study are that (1) age at adoption must be one year or less, (2) the age difference

\footnotetext{
Editor's Note: Nancy L. Segal, Ph.D. is the 2001-2002 recipient of the Award for Outstanding Scholarship and Creativity, in the Division of Humanities and Social Sciences, at California State University, Fullerton. She will be honored with a commemorative plaque at the September, 2002 convocation.
}

Address for correspondence: Nancy L. Segal, Department of Psychology, California State University, Fullerton, CA 92834 USA. Email: nsegal@fullerton.edu 
between the children must be nine months or less and (3) children must be four years of age, or older, at the time of study. Justification for these rules and several others are available elsewhere (see Segal, 2000a, 2000b). A study, "Twins, Virtual Twins and Friends: Peers and Adjustment" is about to begin, in collaboration with Dr. Shirley McGuire, at the University of San Francisco.

\section{Three Alleles}

Chimerism, the appearance of two separate cell lines in a single individual, has been detected in DZ twins. This condition is explained by anastomoses of blood vessels in utero. The first case was reported in 1953 when blood cell admixture was observed in a female twin whose brother had died in infancy (Dunsford et al., 1975). Chimerism in twins has been presumed to occur rarely, but several years ago investigators discovered it in $8 \%(32 / 415)$ of DZ pairs and in 21\% (12/57) of DZ triplets (van Dijk et al., 1996).

A recent paper reported curious findings following DNA testing of a DZ twin male: tests revealed three alleles at four of nine tested loci (Rubocki et al., 2001). This paper appeared in a forensic sciences journal, not in the psychological or medical journals more likely to be read by twin researchers. The paper by van Dijk and colleagues was not cited. I noted this omission in journal correspondence (Segal, in press), later forwarded to Dorret Boomsma. The message subsequently reached Nick Martin who wondered if chimerism might explain the presence of three alleles detected in his adolescent twins' DNA samples, analyzed at the Center for Inherited Disease Research (CIDR). (CIDR performs genome scanning and is supported by twelve of the National Institutes of Health institutions. The center is associated with Johns Hopkins University, in Baltimore.) This turned out not to be the case (the third allele was not detected in the parents and must have been due to contamination), but the chain of events shows how a single case can stimulate further investigation.

\section{Team Teachers}

Alexander and Andrew Fingelkurts are an intellectually gifted and artistically inspired MZ male twin pair. Their life histories and professional contributions were described in an earlier issue of
Twin Research (Segal \& Senina, 2001). Recall that the Fingelkurts' enjoyed faculty research positions within the same department at the Helskinki University of Technology. This situation seems remarkable, given the difficulties that similarly qualified spouses face in seeking common placements. At the time I prepared that article, I recalled two other $\mathrm{MZ}$ twin pairs, one male and one female, whose faculty positions were in the same departments. It is possible that this is not the rare occurrence it appears to be.

Assessing the comparative frequency and success of matched academic appointments and achievements of twins and selected groups of non-twins would be interesting at many levels. A recurrent issue is whether twins are under-represented among academic high achievers. In personal correspondence to this author, Ericsson, (1995) asserted that:

In the traditional domains of Arts and Sciences the number of individuals (one or both members of identical and fraternal twin pairs) attaining the highest levels of achievement is very low and clearly below the frequency predicted by base rates. In sports I have found more examples of one or both twins reaching very high levels.

I have never seen a formal analysis of relevant data, but believe that the Fingelkurts twins and other talented sets could bring clarity to this question.

I did not intend to revisit this issue in the present article, but a recent event brought it to mind. A television producer excitedly explained that he had interviewed a pair of $\mathrm{MZ}$ male twins who believed they were the only twins in the country to team teach a class. The twins are members of the same department in a small southern California college, and conjointly direct instruction online. Identifying this pair yields a sample of four, still small but likely to expand. A comprehensive study of the nature and frequency of twins' intellectual contributions would be challenging and timely.

\section{Jim Twins}

The reared apart "Jim Twins" are an institution, famous for their same first names, their wives' same first names and their sons' same first names. They are also famous for both owning a dog named Toy, driving light blue
Chevrolets, working in law enforcement and writing love letters to their wives. They may be less well known for having launched the Minnesota Study of Twins Reared Apart.

The Jim twins were reunited in Ohio, in February, 1979. Thomas J. Bouchard, Jr., Psychology Professor at the University of Minnesota, was teaching and writing a differential psychology textbook at the time. I was a graduate student at the University of Chicago, but clearly recall the enormous public enthusiasm over this case. There was scientific curiosity over the Jim twins, as well, but Bouchard was the only investigator to act on this interest.

When Bouchard invited the twins to the university for psychological and medical assessment, it was never with the intention of starting a long-term study. The goal was to prepare a compendium of several new reared apart twin cases - assuming other cases could be found. It turned out that the Jim twins' striking similarities and the media's attention to these similarities attracted many other pairs, from the United States and abroad. Thus, the Minnesota Study of Twins Reared Apart grew naturally out of the excitement and momentum generated by a single pair.

\section{Simultaneous Death}

In March, 2002, MZ twin brothers from Finland were killed in similar bicycling accidents on the same road, within two hours of one another. The rarity of such an occurrence explains the rapidity with which this information circulated around the world. According to a police officer, "This [was] simply a historic coincidence" (Reuters, 2002).

I recall a somewhat similar case that could be explained, at least in part, without invoking coincidence. In 1996, MZ twin brothers from Australia succumbed to cardiac arrest within minutes of one another while dining out (New York Daily News, 1996). This second case, while also exceptional, is more easily understood than the first because of the twins' concordance for heart failure. The simultaneous occurrence of their attacks may seem striking to some, although genetically minded chronobiologists and twin researchers might think otherwise. In fact, in an earlier 
issue of Twin Research, I reported the case of 67-year-old MZ twins, Richard and Robert Tenniswood. One twin experienced severe chest pains, later diagnosed as a heart attack. While recovering in the hospital, his twin brother appeared for treatment of the same symptoms (see Segal, 1999).

The possibility that both Finnish twins experienced the same mental lapse or physical impairment that increased the likelihood of their nearly simultaneous accidents cannot be dismissed. This seemingly "odd case" when re-appraised with reference to similar occurrences, transitions from the strange to the scientific. A systematic collection and analysis of such events would be worth pursuing. Such an approach has brought fresh perspec- tives to our understanding of twins' simultaneous loss from sudden infant death syndrome (Koehler et al., 2001).

\section{Case Assortment}

I have come across other intriguing twin cases that might benefit from systematic study. Suggested research questions follow each entry: 1 . A mother delivered male-female twins following fertility drug treatments. She delivered a second male-female set several years later after discontinuing the medication. How frequently does this occur, and what are the mechanisms involved? 2. Mothers in Boston, Massachusetts (Scammel, 2000) and Witchita, Kansas (Associated Press, 2002) delivered naturally conceived quadruplets, composed of two $\mathrm{MZ}$ male twin pairs. Of course, the foursomes also includes four sets of $\mathrm{DZ}$ twins! What is the nature of possible familial links between MZ and DZ twinning? Do these mothers differ biologically from mothers delivering only $\mathrm{MZ}$ or only DZ sets? 3. An interracial couple produced DZ twin boys, one strongly resembling his mother (who was black) and the other strongly resembling his father (who was white) (Shearer, 1983). A Caucasian mother and Hispanic father also produced a very different looking twin pair; these DZ girls participated in one of my studies at California State University, Fullerton. How often does this phenomenon occur and how does if affect parent-child and twin-twin relations? Other investigators surely have other stories to tell.

\section{Research Reviews}

The four research reviews appearing below continue the theme of identifying unusual case studies of twins as a step toward further investigation.

\section{DZ Twins Discordant for Hyperinsulinism}

A link between neonatal hyperinsulinemic hypoglycemia and maternal diabetes is well established. (Hyperinsulinemia is a condition involving too much insulin in the blood; this can lead to hypoglycemia or diminished concentrations of blood glucose; Online Medical Dictionary, 1998-2002.) Hyperinsulinism is thought to explain excessive fetal growth or macrosomia, but macrosomia among infants born to diabetic mothers is not well understood (Mohan et al., 2001).

Mohan et al. (2001) reported a revealing case study of DZ twins discordant for transient hyperinsulinemic hypoglycemia. The boy and girl were born by cesarean section to a 27-yearold mother affected with type I diabetes. The twins were healthy at birth, but the second twin showed a reduction in blood glucose level that required correction. Interestingly, the second twin had shown normal
Doppler flows (ultrasonographic study of blood flow) and birth weight near the 70th centile, while, the unaffected twin showed reverse Doppler flows and birth weight near the 90 th centile. The investigators concluded that factors underlying hyperinsulinemia may differ from those underlying excessive fetal growth. They also suggested that despite decreases in infant symptoms consequent to therapeutic intervention with diabetic mothers, some infants' genetic backgrounds may predispose them to metabolic difficulties. More detailed study of DZ twins discordant for hypoglycemia may elucidate this complex issue.

\section{DZ Twins Born After ICSI (Intracytoplasmic Sperm Injection)}

The increased rate of congenital malformations among twin infants is widely recognized. Now that increasing numbers of twins are arising through assisted reproductive technologies, new questions are emerging. Specifically, to what extent can anomalies in newborn twins be explained by these procedures?

A recent case study is exemplary of these new questions and possible new approaches (Kotzot et al., 2002). DZ twins were prematurely delivered to a primiparous, 37-year-old mother. One twin showed maternal meiosis Iderived trisomy 21, while the co-twin showed multiple congenital abnormalities. Molecular genetic analyses were conducted, indicating that mosaicism and chimerism in the second twin were unlikely. More to the point in question, Kotzot et al. (2002) noted that the mother's risk of a trisomy 21 baby was increased due to her relatively advanced age. They further noted that congenital malformations (especially defects involving the heart and oesophagus that were observed in the second twin) are slightly increased in DZ twin infants with normal karyotypes. Thus, they concluded that the twins' anomalies were unrelated to each other and to ICSI.

This judgment was consistent with a worldwide survey of results from ICSI procedures that appeared in 2000 (Tarlatzis \& Bili, 2000). Specifically, major and minor malformations do not show an increased frequency among infants conceived by ICSI, relative to those conceived by in vitro fertilization or naturally. The rate of chromosomal errors, in particular those involving the sex chromosomes, shows a slight $(2 \%)$ elevation. The authors recommended 
that the number of implanted ICSIderived embryos be limited to (1) reduce the frequency of twin-related problems in newborns, and (2) to better assess the true effects of ICSI on fetal development.

\section{"Simultaneous Madness"}

"Simultaneous Madness in Twin Sisters" describes the simultaneous onset and development of delusional and hallucinatory behaviors in 27-year-old female twins, from Spain (Flórez \& GómezReino, 2001). Arriving at the psychiatric emergency unit, in Ourense, the twins recounted a premonition experienced two nights earlier: their deceased grandfather had been buried alive and their grandmother was responsible. They decided to telephone their family to share this news. While doing so, neighbors heard their shouts and summoned the police. The twins were then transported to a nearby general hospital prior to their referral to Ourense. Other delusions and hallucinations were described. The family revealed that the twins' bizarre behaviors had been ongoing for nearly 18 months.

This interesting case would be worth following were it not for the investigators' failure to document zygosity assessment procedures. The twins were classified as dizygotic, but scientific justification was not provided. Conventional twin concordance estimates for schizophrenia (MZ: 50\%; DZ: 17\%), plus twins' "parallel social and psychological development and a unique personal relationship" (p. 502) are cited by the authors as a prelude to their analysis of the twins' matched psychopathology. Unfortunately, their summation of this provocative case - that shared genes and environments may underlie the twins' similar psychosis — is misleading and uninformative because the twins' zygosity is inconclusive.

\section{Sixteenth Century Conjoined Twins}

Scientific evidence need not come from scientific sources. It was fascinating to learn that conjoined twinning was recognized in medieval England, described within a series of illustrative ballads (Anderson, 2002). The author begins by reminding us that early British societies mostly acquired knowledge of disease through analyses of skeletal remains. However, some conditions, especially major congenital anomalies, while absent from such sources, were "preserved" in documentary and artistic materials. Reference is made to Elizabethan ballads and broadsides that are part of collections located in the British Library, in England, and in the Huntington Library, in California. (Broadside ballads are descriptive or narrative verses or songs on popular themes. They appeared in the 15 th century and were sung or recited in public places or printed for sale. Encyclopedia Britannica, 2002). They include descriptions of unusual human phenomena, including malformations. Birth defects were understood to reflect God's punishment to parents for immorality.

The accompanying figures depicting conjoined twins are intriguing, as they are consistent with current medical classifications. The first shows an omphalopagus pair: co-twins connected at the umbilicus and facing each other. They were born in 1565 , but one lived for only half a day and the other died one hour later. The second shows front and back views of a janiceps pair: co-twins have separate limbs, but a shared chest and head. Janiceps twins take their name from the Roman God, Janus, who, according to myth "looked before and after." This distinguishing feature is visible in the two faces, formed from the left and right sides of each twin (see Segal, 2000). These twins were also born in 1565 , but lived for only two hours. Both sets were female, consistent with the higher frequency of females than males among conjoined sets; a review of 600 publications spanning 500 years found that $70 \%$ of the cases were female (Hoyle, 1990).

The two pairs documented in this paper are not the earliest conjoined twin sets in England. This distinction belongs to the Biddenden Maids, Mary and Eliza Chulkhurst, who were born in $1100 \mathrm{AD}$ and lived until they were 34 (Bryan, 1995). The Chulkhurst Charity was established following their death. Biscuits embossed with the twins' images were distributed to the poor of Biddenden every Easter until the 1900s (Sanders, 1998-2002).

\section{Parenting Twin Pandas}

The giant panda population has been shrinking, due to climatic changes and human activities (Kleiman, 1992). Thus, there is enormous interest in insuring the growth and development of panda twins, born in over half the litters. Unfortunately, panda mothers often reject one infant, jeopardizing its survival. Zoo staffs' attempts to raise the neglected twin have not always been successful because the infant is deprived of the rich nutrients found in the mother's milk.

A solution to this problem was developed by staff at the Chengdu Zoo, in China. When panda QingQing's twins were one month old, one twin was removed and hand-fed by humans for a 24 hour period. It was then returned to its mother while the other twin was removed. This procedure was repeated, allowing each co-twin to benefit from its mother's nourishment and care. When the twins were five and one-half months old, they weighed 21 pounds each and were thriving. Qing-Qing's calm manner was considered critical to the success of this intervention.

Two panda twin myths have recently been dispelled. First, it was thought that infant pandas could not be human-reared from birth. However, the Chengdu staff, in conjunction with experts from other zoos, successfully reared a new-born panda twin. Second, it was believed that 
panda mothers were incapable of raising twins without human assistance.

\section{References}

Anderson, T. (2002). Documentary and artistic evidence for conjoined twins from sixteenth century England. American Journal of Medical Genetics, 109, I55-159.

Associated Press (2002). Multiples in the news: Tests confirm quads born that are two sets of identical twins [electronic version].

Bryan, E. M. (1995). Twins and high multiple, births: $A$ guide to their nature and nurture. London: Baillière Tindall.

Dunsford, I., Bowley, C. C., Hutchison, A. M., Thompson, J. S., Sanger, R., \& Race, R. R. (1953). A human blood-group chimera. British Medical Journal, 2, 8I.

Encyclopædia Britannica. (2002)."broadside ballad" Retrieved May 18, 2002 from http://search.eb.com/eb/article?eu=16792,

Flórez, G., \& Gómez-Reino, I. (200I). Simultaneous madness in twin sisters. European Journal of Psychiatry, 16, 50 I-502.

Hoyle, R. M. (1990). Surgical separation of conjoined twins. Surgery, Gynecology and Obstetrics, 170, 549-562.

Kleiman, D. G. (1992). Giant pandas: Bamboo bears. [electronic version] ZooGoer, 21 .
However, an investigator at the Wolong Nature Reserve observed a mother with

Koehler, S. A., Ladham, S., Shakir, A, \& Wecht, C. H. (200I). Simultaneous sudden infant death syndrome: A proposed definition and worldwide review of cases. American Journal of Forensic Medicine and Pathology, 22, 23-32.

Kotzot, D., Schönekerl, S., Faber, R., Hausen, D., Kujat, A., \& Froster, U. G. (2002). Dizygotic twin boys born after ICSI with maternal meiosis I-derived free trisomy $2 \mathrm{I}$ in the first and multiple congenital anomalies in the second: Chance or common aetiology? Human Reproduction, I7, 902-915.

Mohan, M. S., Praveen V., Jog, S. M., \& Patole, S. K. (200I). Discordance for transient hyperinsulinism in dizygotic twins of a diabetic mother. Prenatal and Neonatal Medicine, 6, 356-357.

New York Daily News (1996, May 28). Twins die together while dining.

Reuters (2002, March 6). Double tragedy [electronic version].

Rubocki, R. J., McCue, B. J., Duffy, K. J., et al. (200I). Natural DNA mixtures generated in fraternal twins in utero. Journal of Forensic Sciences, 46, I 20- 125.

Sanders, C. (1998-2002). History of conjoined twins (900-1499). Retrieved from http:// www.twinstuff.com/conj- I I00.htm two apparently healthy panda cubs. Qing-Qing's twins were born shortly thereafter.

Scammel, C. L. (November, 2000). Wow, I'm having 4 babies. Parents, 223-224, 226.

Segal, N. L. (1999). Kin recognition by olfactory cues: What can twins tell us? Twin Research Journal, 2, 293-298.

Segal, N. L. (2000a). Entwined lives: Twins and what they tell us about human behavior. NY: Plume.

Segal, N.L. (2000b). Virtual twins: New findings on within-family evironmental influences on intelligence. Journal of Educational Psychology, 92, 442-448.

Segal, N. L., \& Senina, I. N. (2002). Russian twin studies: Colleagues, controversies, case studies and current events. Twin Research, 5, 53-64.

Shearer, L. (1983). Intelligence report. Parade Magazine.

Tarlatzis, B. C., \& Bili, H. (2000). Intracytoplasmic sperm injection. Survey of world results. Annals of the New York Academy of Sciences, 900, 336-344.

van Dijk, B.A., Boomsma, D. I., \& de Man,A. J. M. (1966). Blood group chimerism in human multiple births is not rare. American Journal of Medical Genetics, 6I, 264-268. 